\title{
O impacto cognitivo do bilinguismo no envelhecimento e a aquisição de segunda língua por aprendizes idosos
}

\author{
The cognitive impact of bilingualism on aging and second language acquisition by older learners
}

\section{Lívia Schleder de Borba}

Pontifícia Universidade Católica do Rio Grande do Sul - PUCRS - Porto Alegre - Rio Grande do Sul - Brasil

\begin{abstract}
Resumo: Este artigo objetiva apresentar, através de uma revisão da literatura disponível, o que se sabe até o momento acerca do impacto cognitivo do bilinguismo ao longo da vida no envelhecimento e das peculiaridades do aprendiz idoso em seu processo de aquisição de segunda língua. Pesquisas recentes mostram que o bilinguismo pode atuar como um mecanismo protetor contra os declínios cognitivos associados ao envelhecimento. No entanto, há estudos que contestam essa visão e mostram a necessidade de novas investigações. Apesar dos numerosos estudos sobre bilinguismo e envelhecimento, é notória a falta de estudos acerca da aquisição de uma segunda língua por aprendizes idosos. Sabe-se que o desempenho cognitivo de idosos difere daquele de jovens adultos. Mais especificamente, estudos mostram déficits nas funções executivas e diminuição da velocidade de processamento (PARK; REUTERLORENZ, 2014). Por isso, faz-se necessário perceber as peculiaridades do aprendiz idoso para investigar o seu processo de aquisição de uma segunda língua.
\end{abstract}

Palavras-chave: Bilinguismo. Envelhecimento. Aquisição de segunda língua. Aprendizes idosos.

Abstract: This article aims to present, through a review of the available literature, what is known so far about the cognitive impact of lifelong bilingualism on aging and the peculiarities of older learners in their second language acquisition process. Recent research shows that bilingualism can act as a protective mechanism against cognitive decline associated with aging. However, there are studies that contest this view and show the need for further investigation. Despite the numerous studies on bilingualism and aging, there is a notable lack of studies on the acquisition of a second language by older learners. It is known that the cognitive performance of older adults differs from that of young adults. More specifically, studies show deficits in executive functions and decreased processing speed (PARK; REUTER-LORENZ, 2014). Therefore, it is necessary to understand the peculiarities of the older learn in order to investigate their process of acquiring a second language.

Keywords: Bilingualism. Aging. Second language acquisition. Older learners. 


\section{Introdução}

Pretende-se com este artigo fazer uma breve revisão bibliográfica dos estudos que buscaram investigar o impacto cognitivo do bilinguismo no envelhecimento e a aquisição de segunda língua por aprendizes idosos. O interesse em analisar tal questão é justificado por dois motivos. Em primeiro lugar, sabese que o número de adultos idosos, ou seja, o número de pessoas com mais de sessenta e cinco anos, está em ascensão, conforme mostram os dados do Instituto Brasileiro de Geografia e Estatística (IBGE), segundo o qual houve um aumento de $2,4 \%$ no número de idosos de 1991 a 2010 (GARCIA, 2017). Dessa forma, se fazem necessárias medidas em todos os campos do conhecimento que tenham como objetivo atender a essa população. No que diz respeito ao tema do presente artigo, revela-se importante que os estudos acerca da aquisição de segunda língua por esses indivíduos sejam ampliados uma vez que já são conhecidos os benefícios do conhecimento de uma segunda língua para a cognição no envelhecimento. Segundo Ardilla e Ramos (2010), pesquisas recentes mostram que o bilinguismo pode funcionar como um mecanismo de proteção contra as perdas cognitivas características do envelhecimento.

Para fins de esclarecimento teórico, faz-se a distinção de bilinguismo e aquisição de segunda conforme Lourdes Ortega (2014). Estudos com foco no bilinguismo e, portanto, em indivíduos bilíngues, tendem a debruçar-se no que a autora chama de produtos do bilinguismo. Assim, nas investigações que associam bilinguismo e envelhecimento, tende-se a observar o cérebro bilíngue levando em consideração determinadas variáveis, como idade de aquisição, domínio das línguas em questão ou nível de proficiência, com o objetivo de compreender como o conhecimento de duas ou mais línguas pode afetar, de forma positiva ou negativa, o processo de envelhecimento. Já a aquisição de segunda língua, ainda conforme Ortega, busca entender os caminhos tomados por aprendizes durante o seu processo de aprendizagem. Pode-se, então, dizer que a ênfase está no processo e não no produto. Extensos e numerosos são os estudos sobre aquisição de segunda língua por crianças, adolescentes e jovens adultos, mas, como afirmam Kliesch et al (2018), o estudo da aquisição de segunda língua por adultos idosos, tomada aqui, então, como as peculiaridades do processo de aprendizagem por esse tipo de aprendiz, ainda é incipiente.

A revisão bibliográfica aqui apresentada será iniciada com uma apresentação de estudos que revelam as características do envelhecimento saudável e, mais especificamente, com uma elucidação de como a linguagem é afetada pelos déficits cognitivos associados ao envelhecimento. Em seguida, serão explicados os mecanismos compensatórios estudados por Reuter-Lorenz e Park (2014) e Stern (2009), que buscam compreender como o cérebro idoso lida com as perdas cognitivas associadas ao envelhecimento e como a aquisição de segunda língua pode atuar como um desses mecanismos. A seguir, é feita uma reunião dos resultados de diferentes estudos que relacionam bilinguismo e envelhecimento. Por último, é proposta uma discussão acerca da aquisição de segunda língua por idosos com a apresentação de novos estudos na área.

\section{As características do envelhecimento saudável}

Sabe-se que o desempenho cognitivo de indivíduos idosos é diferente daquele de jovens adultos. Estudos mostram que existem declínios cognitivos associados ao envelhecimento, como problemas de memória, déficits nas funções cognitivas e diminuição na velocidade de processamento (REUTER-LORENZ; PARK, 2014). Além disso, o processo típico de envelhecimento envolve, em uma perspectiva neurobiológica1, "atrofia do cérebro, especialmente em áreas frontais do cérebro e regiões que auxiliam a memória declarativa, perda de

\footnotetext{
1 As traduções são responsabilidade da autora.
} 
conexões sinápticas e a emergência de sintomas neuropatológicos associados à demência" (ANTONIOU; WRIGHT, 2017, p. 01). Estudos também mostram que as funções executivas - aquelas relativas ao controle inibitório, à memória de trabalho e à flexibilidade cognitiva - também são afetadas durante o envelhecimento (DRAG; BIELIAUSKAS, 2010).

No que diz respeito à linguagem, Burke e Shafto (2004) mostraram que adultos idosos apresentam falhas na recuperação de palavras, caracterizando uma dificuldade na produção oral e escrita de palavras. Uma dessas falhas é o fenômeno tip-of-the-tongue (TOT), ou ponta da língua, em que o falante falha ao tentar produzir uma palavra conhecida. Em um estudo de Shafto et al. (2010), demonstrou-se que indivíduos mais velhos sofrem mais com o fenômeno TOT porque apresentam redução na massa cinzenta, o que afeta a habilidade de modular a atividade neural quando a recuperação da palavra se torna difícil. No aspecto fonológico, quando participantes de um estudo de MacKay e James (2004) foram solicitados a trocar sons semelhantes entre palavras (como/p/ por /b/), percebeu-se que os participantes mais velhos omitiam os sons, o que sugere uma dificuldade em recuperar a fonologia das palavras. Por fim, no campo discursivo e em tarefas de nomeação de figuras, indivíduos mais velhos apresentaram mais dificuldades que indivíduos mais jovens ao produzirem mais ambiguidades, fazerem mais pausas e hesitações (BURKE; SHAFTO, 2004).

Em contrapartida, o processamento semântico permanece inalterado durante o envelhecimento. A recuperação do sentido das palavras e "outros processos semânticos envolvidos na compreensão da linguagem apresentam pouca alteração no envelhecimento" (BURKE; SHAFTO, 2004, p.01). Assim, diferentemente da memória episódica, aquela relativa à memória de eventos autobiográficos e onde são observadas perdas em indivíduos idosos, a memória semântica, que armazena o conhecimento de mundo, inclusive o sentido das palavras, pode não ser prejudicada (DRAG; BIELIAUSKAS, 2010). Ao investigar o funcionamento da memória semântica, Park et al. (2003) demonstraram que habilidades semânticas como o vocabulário apresentaram um padrão contrário daquele da memória de trabalho e da velocidade de processamento, ou seja, foram aprimoradas pelo envelhecimento. Essa melhora é justificada pelos autores pelo acúmulo de conhecimento factual ao longo da vida.

Dessa forma, é possível concluir a partir desses estudos que o processo de envelhecimento é marcado por alterações cerebrais estruturais que afetam o desempenho cognitivo dos indivíduos idosos. Essas alterações no nível cognitivo, por sua vez, podem influenciar o desempenho linguístico desses sujeitos, especialmente no que tange a produção de palavras familiares e a produção discursiva, ainda que se tenha demonstrado que o nível semântico permaneça inalterado. A seguir, serão apresentados mecanismos fundamentais para a compreensão do desempenho cognitivo de indivíduos idosos: a teoria de andaimento do envelhecimento, primeiramente proposta por Reuter-Lorenz e Park em 2009 e aprimorada em 2014, e o conceito de reserva cognitiva de Stern (2009).

\section{Mecanismos compensatórios: teoria de andaimento (scaffolding) do envelhecimento e cognição e reserva cognitiva}

A Teoria de Andaimento do Envelhecimento e da Cognição, proposta por Reuter- Lorenz e Park em 2009 e depois revista em 2014, "explica como os efeitos combinados de processos neurais adversos e compensatórios produzem diferentes níveis de função cognitiva" (REUTER-LORENZ; PARK, 2014, p. 355). O mecanismo compensatório descrito pela teoria funciona como uma forma de plasticidade cerebral positiva, na medida em que opera para contra-atacar os efeitos adversos do envelhecimento, chamados pelas autoras de desafios neurais e deterioração funcional, que, por sua vez, podem ser descritos como uma forma negativa de plasticidade cerebral. Os desafios neurais são explicados pelas autoras como as mudanças estruturais que ocorrem no cérebro durante o envelhecimento, enquanto a deterioração funcional refere-se às perdas em atividades cerebrais relacionadas ao envelhecimento. 
Assim, o andaimento compensatório pode se dar por uma maior ativação ou recrutamento adicional de regiões cerebrais pré-frontais, pelo recrutamento bilateral de regiões que costumam ter atividade lateralizada em jovens adultos e pela neurogênese (REUTER-LORENZ; PARK, 2014). As mudanças estruturais negativas observadas no envelhecimento, então, servem como um estímulo à criação de mecanismos compensatórios com o objetivo de manter as funções cognitivas. No modelo original da teoria, sugere-se que o andaimento pode ser aprimorado por meio de "intervenções explícitas que incluem diversas atividades como exercício físico, engajamento intelectual e novos aprendizados" (REUTER-LORENZ; PARK, 2014, p. 356). Assim, é possível pensar que o aprendizado de uma segunda língua na terceira idade possa servir como uma dessas intervenções que facilitam a compensação dos declínios advindos do envelhecimento.

É importante ressaltar que o andaimento compensatório resulta da deterioração neurofisiológica resultante do envelhecimento e que atitudes positivas ao longo da vida, com um impulso de uma genética favorável, podem atuar como medidas protetivas contra essa deterioração, o que consequentemente diminui a necessidade da atuação de mecanismos compensatórios. É por isso que o modelo revisado da teoria inclui variáveis de estilo de vida que "podem impactar a estrutura e o funcionamento do cérebro em envelhecimento" (REUTER-LORENZ; PARK, 2014, p. 360). Segundo as autoras, há um número considerável de estudos que sugerem que indivíduos engajados em atividades intelectuais e sociais durante a vida adulta têm um desempenho cognitivo melhor e que indivíduos com maior nível de escolaridade tendem a ser diagnosticados com demência mais tarde que indivíduos com baixa escolaridade (REUTERLORENZ; PARK, 2014). Além disso, "altos níveis de exercício físico cardiovascular, multilinguismo e o engajamento em atividades de lazer já tiveram resultados benéficos para o envelhecimento cognitivo" (REUTER-LORENZ; PARK, 2014, p. 361).

O conceito de reserva cognitiva de Stern (2009) é usado para explicar a observação de que alguns indivíduos têm melhor desempenho cognitivo que outros na presença de patologia cerebral. "A reserva cognitiva refere-se à habilidade de fazer um uso flexível e eficiente de redes cognitivas durante a execução de tarefas na presença de patologia cerebral" (STERN, 2009, p. 50). Em um estudo de 1994 com indivíduos de sessenta anos ou mais (STERN et al., 1994), demonstrou-se que o risco de demência em indivíduos com baixa escolaridade (menos de oito anos) era duas vezes mais alto que em indivíduos com alta escolaridade e que o risco de demência também era maior em indivíduos com baixo engajamento profissional ao longo da vida. A hipótese de Stern e seus colegas foi de que os engajamentos intelectual e profissional aumentam a reserva cognitiva na presença de demência. Em um estudo que investigava o papel de atividades de lazer na vida de indivíduos com mais de 65 anos (SCARMEAS et al, 2001), demonstrou-se que o envolvimento em atividades de lazer pode reduzir o risco de demência incidente.

Os estudos mostram, dessa forma, que o envolvimento em atividades intelectuais e de lazer, mesmo na terceira idade, pode impactar a reserva cognitiva. Assim, conforme Stern (2009), essas descobertas dão suporte à possibilidade de que sejam possíveis intervenções mesmo em indivíduos já idosos com o objetivo de enriquecer a reserva cognitiva, desacelerar o declínio cognitivo e prolongar um envelhecimento saudável.

Os mecanismos compensatórios de andaimento e reserva cognitiva dialogam na medida em que consideram que as atitudes tomadas ao longo da vida podem desacelerar 0 processo de envelhecimento e atrasar a aparição dos primeiros sintomas de demência. No primeiro mecanismo, percebe-se que o engajamento do indivíduo ao longa da vida em atividades de lazer e de cunho profissional e intelectual pode tanto diminuir o declínio cognitivo advindo do envelhecimento, fazendo com que medidas compensatórias se tornem menos necessárias, quanto aumentar a capacidade de andaimento compensatório (REUTER-LORENZ; PARK, 2014). Já a reserva cognitiva, ou "estratégias cognitivas compensatórias" 
(REUTER-LORENZ; PARK, 2014, p. 362), que permite que indivíduos tenham melhor desempenho cognitivo diante de patologia cerebral, também pode ser aprimorada por atitudes como engajamento intelectual e profissional.

Para o presente estudo, é especialmente relevante o fato de que tanto a teoria de andaimento quanto a proposta de reserva cognitiva entendem que a plasticidade cerebral está presente no cérebro idoso. No andaimento compensatório, ainda no seu primeiro modelo, são previstas intervenções posteriores aos desafios neurais e à deterioração funcional, portanto em indivíduos já idosos, como novos aprendizados e treinamento cognitivo, que podem aprimorar 0 processo de andaimento (REUTER-LORENZ; PARK, 2014). De maneira semelhante, a proposta de reserva cognitiva sugere que intervenções ainda que tardias podem aprimorar a construção da reserva e, portanto, servir como proteção contra o aparecimento de sintomas de patologia cerebral. Tais constatações fundamentam o benefício do aprendizado de uma segunda língua por idosos. "O aprendizado de uma segunda língua é um processo cognitivo que requer memorização, inibição de L1, atenção prolongada em um ambiente de sala de aula, aprendizado e aplicação de regras, reconhecimento de padrões, metacognição etc." (KLIESCH et al., 2017, p. 50). Dessa forma, não apenas as atitudes tomadas pelos indivíduos ao longo da vida como também aquelas que fazem parte da vida durante o envelhecimento podem ter uma influência positiva no desempenho cognitivo.

\section{Bilinguismo e Envelhecimento}

Indivíduos bilíngues costumam ter desempenho melhor que monolíngues em tarefas que envolvem atenção e controle executivo (ARDILLA; RAMOS, 2010). Segundo os autores, pesquisas sugerem que a habilidade de usar duas ou mais línguas pode resultar em vantagens sociais e cognitivas durante 0 envelhecimento típico e atípico, uma vez que o uso de mais de uma língua pode ampliar os contextos de socialização e atuar como uma forma de reserva cognitiva. Tais benefícios se justificariam pelo fato de que o uso de duas ou mais línguas exige um controle de atenção constante, o que levaria ao aprimoramento das habilidades executivas (BILLIG; SCHOLL, 2011). Segundo Diamond (2006), essas habilidades são colocadas em prática na execução de tarefas novas e em situações que envolvem concentração, planejamento, resolução de problemas, coordenação, mudança, escolhas conscientes ou na superação de impulsos internos e externos. Assim, são chamados de funções executivas o controle inibitório, a memória de trabalho e a flexibilidade cognitiva.

Estudos recentes demonstraram que 0 bilinguismo pode atuar como um fator protetivo contra o declínio cognitivo característico ao envelhecimento e atrasar os primeiros sintomas atribuídos à Doença de Alzheimer (CRAIK et al., 2010; BIALYSTOK et al., 2007; ALLADI et al., 2013). Em Craik, Bialystok e Freedman (2010), os pesquisadores concluíram que o bilinguismo ao longo da vida pode atrasar o aparecimento da Doença de Alzheimer, demonstrando que os pacientes bilíngues foram diagnosticados com Alzheimer em média 4,3 anos mais tarde e apresentaram os primeiros sintomas em média 5,1 anos mais tarde que os pacientes monolíngues, o que sugeriria que o domínio e o uso de duas línguas ao longo da vida pode contribuir para o enriquecimento da reserva cognitiva e, dessa forma, proporcionar aos bilíngues a capacidade de lidar melhor com patologias cerebrais. Já Alladi et al (2013) concluíram que os pacientes bilíngues desenvolveram demência 4,5 anos depois que os pacientes monolíngues e que o efeito dessa vantagem podia ser observado independentemente de outros fatores, como escolaridade e sexo.

Em 2004, foi publicado um importante estudo de Bialystok et al., que sugeria que o bilinguismo pode reforçar as funções executivas, dessa forma compensando pelos efeitos negativos do envelhecimento. Durante um teste de função executiva, o teste de Simon, os participantes bilíngues tiveram melhor desempenho e apresentaram respostas melhores diante de altas demandas de memória de trabalho, e essa vantagem bilíngue ficou mais evidente em indivíduos mais velhos (entre $60 \mathrm{e}$ 
88 anos). Assim, os autores propuseram que o controle do processamento é executado de forma mais eficiente por indivíduos bilíngues, o que poderia sugerir que o bilinguismo pode atrasar perdas relativas às funções executivas durante o envelhecimento.

No que diz respeito ao bilinguismo e sua relação com o envelhecimento típico ou atípico, Ardilla e Ramos (2010), afirmam que bilíngues mais velhos podem fazer um uso positivo do conhecimento de duas línguas para aumentar a produção verbal, enquanto indivíduos acometidos por demência não tiram proveito desse conhecimento. Ao citar um trabalho de DePicciotto e Friedland (2001), os pesquisadores sugeriram que alguns sujeitos bilíngues saudáveis usaram o code-switching como uma estratégia; já os indivíduos com Alzheimer não conseguiram fazer uso do domínio de duas línguas para melhorar seu desempenho cognitivo. Segundo Ardilla e Ramos (2010), já foi observado que um indício inicial de demência é a dificuldade em comunicar-se usando a segunda língua, ou seja, se observa em indivíduos bilíngues uma regressão para a sua primeira língua.

Ainda que os estudos que associam 0 bilinguismo e o atraso na manifestação de demência ou sintomas da Doença de Alzheimer tenham ganhado relevância na área da neuropsicolinguística, segundo Antoniou e Wright (2017), um número crescente de estudos não tem conseguido replicar tais resultados. Por exemplo, Lawton et al (2015), em estudo coorte com amostras de não-imigrantes, não encontraram diferenças significativas no início de sintomas de demência entre monolíngues e bilíngues. Sanders et al (2012) também não encontraram associação entre falantes não nativos de inglês e a incidência de demência ou Doença de Alzheimer. Billig e Scholl (2011) tentaram investigar a influência do bilinguismo no controle inibitório e na memória de trabalho de idosos. O estudo comprovou que os sujeitos idosos (entre 60 e 71 anos), conforme o esperado, tiveram um desempenho inferior quando comparados com sujeitos mais jovens, mas, diferente do esperado, a vantagem bilíngue não foi observada, ou seja, na observação dentro dos dois grupos, monolíngues e bilíngues não apresentaram resultados diferentes. No que concerne a memória de trabalho, as autoras não conseguiram replicar os resultados de Bialystok et al (2004), e monolíngues e bilíngues apresentaram resultados semelhantes. Nas tarefas de controle inibitório, monolíngues e bilíngues também não tiveram resultados relevantemente diferentes, com a exceção de que os bilíngues mais velhos foram um pouco mais rápidos em testes congruentes e incongruentes, o que poderia ser explicado por uma maior eficiência no sistema de monitoramento de conflitos (COSTA, 2008). É possível que as relações encontradas entre bilinguismo e a manifestação de sintomas de demência e Doença de Alzheimer estejam sendo mascaradas pela associação entre escolaridade e bilinguismo e a dificuldade em se encontrar medidas objetivas para 0 que caracteriza o indivíduo bilíngue (GOLLAN et al, 2011). Além disso, Bak (2016) afirma que os resultados inconstantes demonstram a necessidade de que sejam estudadas variáveis como heterogeneidade individual, migração, fatores sociais, diferenças em inteligência e a questão da causalidade reversa. A despeito das questões controversas quanto a uma vantagem do indivíduo bilíngue, ficou demonstrado que o "bilinguismo promove vantagens nas funções executivas, e estas podem contribuir na construção de uma reserva cognitiva, o que, consequentemente, pode atrasar a manifestação dos sintomas de demência (ANTONIOU; WRIGHT, 2017, p. 4)". O que permanece em debate, no entanto, é como isso acontece.

Ardilla e Ramos (2010) afirmam que o padrão de uso das diferentes línguas pode mudar ao longo da vida: "tipicamente, as duas línguas podem ser associadas a diferentes contextos sociais e situações de vida; por exemplo, a L1 pode ser a língua usada em ambiente familiar, enquanto a L2 pode ser usada em ambiente profissional" (p. 75). Assim, o envelhecimento também pode ser associado à regressão à primeira língua e a uma interferência negativa entre as línguas. Como já afirmado anteriormente, isso parece não afetar os indivíduos saudáveis, pelo contrário, o controle executivo necessário à inibição de uma língua em detrimento da outra parece ser benéfico à produção verbal. 
Outros fatores que rodeiam as condições em que o indivíduo se torna bilíngue também se tornam relevantes. Em estudo de Rosseli et al. (2000), a fluência verbal de bilíngues mais velhos foi testada por meio da descrição verbal de uma figura, pela geração de palavras dentro de categorias fonêmicas e semânticas e pela repetição em um teste de repetição de frases. Os resultados demonstraram que os bilíngues tiveram melhor desempenho no teste de fluência semântica e que bilíngues que aprenderam a sua segunda língua antes dos doze anos tiveram um desempenho significativamente melhor no teste de descrição de figuras e de repetição. Tal estudo traz para a balança o fator da idade de aquisição para avaliação dos benefícios do bilinguismo. Já Gollan et al. (2007) avaliaram a questão do equilíbrio no domínio das duas línguas - aqui inglês e espanhol - em indivíduos com uma média de 74 anos de idade por meio do teste de nomeação de Boston. Eles concluíram que os bilíngues com domínio semelhante das duas línguas nomearam mais figuras no total, mas nomearam menos figuras em sua língua dominante que os bilíngues com domínio desigual das duas línguas. Assim, cabe também a consideração da questão do domínio e do equilíbrio entre as duas línguas nos estudos do impacto do bilinguismo.

$\mathrm{Na}$ Tabela 1, encontra-se um panorama resumido dos estudos apresentados nessa seção.

Tabela 1 - Resumo dos estudos sobre o impacto cognitivo do bilinguismo no envelhecimento

\begin{tabular}{|c|c|c|}
\hline Autores & Objetivos & Resultados \\
\hline Alladi et al. (2013) & $\begin{array}{l}\text { Determinar a associação entre bilinguismo e } \\
\text { idade dos primeiros sintomas de demência e } \\
\text { seus subtipos, levando em conta potenciais } \\
\text { fatores confusos. }\end{array}$ & $\begin{array}{l}\text { Pacientes bilíngues desenvolveram } \\
\text { demência } 4,5 \text { anos mais tarde que pacientes } \\
\text { monolíngues, efeito que foi observado } \\
\text { independentemente de outros fatores. }\end{array}$ \\
\hline $\begin{array}{l}\text { Bialystok et al. } \\
(2004)\end{array}$ & $\begin{array}{l}\text { Determinar se o bilinguismo atenua os efeitos } \\
\text { negativos do envelhecimento no controle } \\
\text { cognitivo de adultos idosos. }\end{array}$ & $\begin{array}{l}\text { O bilinguismo foi associado a um menor efeito } \\
\text { Simon para adultos jovens e idosos; } \\
\text { participantes bilíngues responderam com } \\
\text { mais rapidez a condições que exigiam mais } \\
\text { da memória de trabalho; a vantagem bilíngue } \\
\text { foi maior para participantes mais velhos; } \\
\text { controle do processamento é executado de } \\
\text { forma mais eficiente por indivíduos bilíngues, } \\
\text { o que poderia sugerir que o bilinguismo pode } \\
\text { atrasar perdas relativas às funções } \\
\text { executivas durante o envelhecimento. }\end{array}$ \\
\hline $\begin{array}{l}\text { Bialystok et al. } \\
(2007)\end{array}$ & $\begin{array}{l}\text { Examinar o efeito do bilinguismo na } \\
\text { manutenção do funcionamento cognitivo e no } \\
\text { atraso do aparecimento dos primeiros } \\
\text { sintomas de demência no envelhecimento. }\end{array}$ & $\begin{array}{l}\text { Pacientes bilíngues apresentaram um atraso } \\
\text { de } 4,1 \text { anos no aparecimento dos sintomas de } \\
\text { demência em comparação com monolíngues. }\end{array}$ \\
\hline $\begin{array}{l}\text { Billig e Scholl } \\
(2011)\end{array}$ & $\begin{array}{l}\text { Investigar a influência do bilinguismo no } \\
\text { desempenho de idosos ( } 60-71 \text { anos) e } \\
\text { adultos ( } 40-55 \text { anos) em tarefas envolvendo } \\
\text { dois componentes das funções executivas: } \\
\text { controle inibitório e memória de trabalho. }\end{array}$ & $\begin{array}{l}\text { Bilíngues e monolíngues tiveram } \\
\text { desempenho semelhante na tarefa de } \\
\text { memória de trabalho. Quanto ao controle } \\
\text { inibitório, participantes bilíngues foram } \\
\text { ligeiramente mais rápidos que os } \\
\text { monolíngues nas tarefas. }\end{array}$ \\
\hline
\end{tabular}




\begin{tabular}{|c|c|c|}
\hline $\begin{array}{l}\text { Billig e Scholl } \\
(2011)\end{array}$ & $\begin{array}{l}\text { Investigar a influência do bilinguismo no } \\
\text { desempenho de idosos ( } 60-71 \text { anos) e } \\
\text { adultos ( } 40-55 \text { anos) em tarefas envolvendo } \\
\text { dois componentes das funções executivas: } \\
\text { controle inibitório e memória de trabalho. }\end{array}$ & $\begin{array}{l}\text { Bilíngues e monolíngues tiveram } \\
\text { desempenho semelhante na tarefa de } \\
\text { memória de trabalho. Quanto ao controle } \\
\text { inibitório, participantes bilíngues foram } \\
\text { ligeiramente mais rápidos que os } \\
\text { monolíngues nas tarefas. }\end{array}$ \\
\hline Craik et al. (2010) & $\begin{array}{l}\text { Apresentar evidências de que o bilinguismo é } \\
\text { um fator que contribui para a criação de } \\
\text { reserva cognitiva. }\end{array}$ & $\begin{array}{l}\text { Pacientes bilíngues com Doença de } \\
\text { Alzheimer foram diagnosticados } 4,3 \text { anos } \\
\text { mais tarde e relataram o aparecimento dos } \\
\text { primeiros sintomas } 5,1 \text { anos mais tarde que } \\
\text { pacientes monolíngues. }\end{array}$ \\
\hline $\begin{array}{l}\text { De Piccioto e } \\
\text { Friedland (2001) }\end{array}$ & $\begin{array}{l}\text { Investigar as habilidades de fluência verbal } \\
\text { em } 30 \text { bilíngues saudáveis e } 6 \text { bilíngues com } \\
\text { Doença de Alzheimer. }\end{array}$ & $\begin{array}{l}\text { Não houve uma diferença significativa entre } \\
\text { monolíngues e bilíngues. Indivíduos } \\
\text { saudáveis bilíngues usaram code switching } \\
\text { como uma estratégia, enquanto aqueles com } \\
\text { DA não fizeram uso dessa estratégia. }\end{array}$ \\
\hline $\begin{array}{l}\text { Gollan et al. } \\
(2007)\end{array}$ & $\begin{array}{l}\text { Determinar como o desempenho de sujeitos } \\
\text { bilíngues idosos é afetado pelo conhecimento } \\
\text { de duas línguas. }\end{array}$ & $\begin{array}{l}\text { Bilíngues com domínio semelhante das duas } \\
\text { línguas nomearam mais figuras no total, mas } \\
\text { nomearam menos figuras em sua língua } \\
\text { dominante que os bilíngues com domínio } \\
\text { desigual das duas línguas. }\end{array}$ \\
\hline $\begin{array}{l}\text { Gollan } \\
(2011)\end{array}$ et al. & $\begin{array}{l}\text { Investigar a relação entre a proficiência } \\
\text { linguística bilíngue e o aparecimento dos } \\
\text { primeiros sintomas da Doença de Alzheimer } \\
\text { em } 44 \text { bilíngues. }\end{array}$ & $\begin{array}{l}\text { Níveis mais altos de bilinguismo foram } \\
\text { associados a diagnóstico e aparecimento dos } \\
\text { primeiros sintomas de Alzheimer mais tardios } \\
\text { em participantes com menor nível de } \\
\text { escolaridade. }\end{array}$ \\
\hline $\begin{array}{l}\text { Lawton et al. } \\
(2015)\end{array}$ & $\begin{array}{l}\text { Determinar se os diagnósticos clínicos de DA } \\
\text { e demência ocorreram mais tarde para } \\
\text { bilíngues do que para monolíngues. }\end{array}$ & $\begin{array}{l}\text { Não foram encontradas diferenças } \\
\text { significativas entre bilíngues e monolíngues. }\end{array}$ \\
\hline $\begin{array}{l}\text { Sanders et al. } \\
(2012)\end{array}$ & $\begin{array}{l}\text { Investigar a hipótese de que falantes não } \\
\text { nativos de inglês têm risco mais baixo de } \\
\text { desenvolver demência e DA que falantes } \\
\text { nativos de inglês. }\end{array}$ & $\begin{array}{l}\text { Concluiu-se que o uso não nativo de inglês } \\
\text { não parece ser um preditor independente de } \\
\text { risco (ou proteção) para demência ou DA. } \\
\text { Detectou-se uma associação entre a } \\
\text { escolaridade dos falantes não nativos e o } \\
\text { risco de demência. Falantes não nativos com } \\
\text { pelo menos } 16 \text { anos de educação formal tiver } \\
\text { o risco aumentado em quatro vezes quando } \\
\text { comparados com falantes não nativos com } \\
\text { menor nível de escolaridade. }\end{array}$ \\
\hline $\begin{array}{l}\text { Rosselli et al. } \\
(2000)\end{array}$ & $\begin{array}{l}\text { Examinar o impacto do bilinguismo em testes } \\
\text { de fluência verbal e repetição em bilíngues } \\
\text { hispânicos idosos. }\end{array}$ & $\begin{array}{l}\text { Participantes monolíngues e bilíngues } \\
\text { tiveram desempenho igual em todos os testes } \\
\text { com exceção do teste de fluência verbal } \\
\text { semântica. Bilíngues que aprenderam a } \\
\text { segunda língua (inglês) antes dos } 12 \text { anos } \\
\text { tiveram desempenho significativamente } \\
\text { melhor. }\end{array}$ \\
\hline
\end{tabular}

Fonte: Elaborado pela autora. 


\section{A aquisição de segunda língua por aprendizes idosos}

Enquanto os estudos acerca do impacto do bilinguismo no processo de envelhecimento dão ênfase aos resultados do processo de aprendizado de uma segunda língua, escassos são os estudos que buscam investigar como o processo de aprendizado per se se dá quando o aprendiz já atingiu a terceira idade. Uma possível explicação para o aparente desinteresse nesta questão no campo dos estudos de aquisição de segunda língua é a supervalorização do papel da idade no processo de aprendizagem. Segundo Kliesch et al. (2018), a idade é percebida como um preditor para o sucesso na aquisição de segunda língua em detrimento de outros fatores como a natureza do input, a qualidade da formação do professor, o comprometimento de tempo e energia, as diferenças individuais, os níveis de motivação, entre outros.

Os pais do chamado período crítico para a aquisição de linguagem, Penfield e Lenneberg, fizeram as suas primeiras asserções sobre o tema nos anos 50 e 60 (SINGLETON; PFENNINGER, 2018). Ainda que esses primeiros estudos se detivessem na aquisição de primeira língua, muito do que foi proposto pelos pioneiros pesquisadores foi adotado pela pesquisa em aquisição de segunda língua. Segundo Singleton e Pfenninger (2018), hoje já se sabe que os principais postulados que suportavam a teoria do período crítico já não se sustentam mais. Em primeiro lugar, a ideia de Penfield de que o cérebro perdia a sua plasticidade no fim da infância já não tem mais amparo. Ainda que ela tenha servido como uma fundamentação sólida para a criação de políticas comerciais e públicas com o foco no ensino precoce de uma segunda língua, hoje se sabe que - e os autores afirmam que há consenso - o cérebro mantém a sua plasticidade ao longo da vida. Em segundo lugar, a afirmação de Lenneberg de que a lateralização das funções da linguagem impedia que o aprendiz atingisse um nível semelhante ao do falante nativo também não encontra sustentação em pesquisas recentes (idem, 2018). Ao contrário, a observação de que indivíduos mais velhos - considerados aqui os que superaram a infância e a puberdade - possam ter dificuldades em atingir o que se costuma chamar de semelhança com o falante nativo é embasada pela presença de outros fatores, notadamente sociais e culturais.

De acordo com Kliesch et al. (2018), há duas perguntas a serem respondidas no que diz respeito a aquisição de segunda língua por aprendizes idosos. A primeira seria quanto à capacidade de aprendizes idosos aprenderem uma segunda língua; a segunda seria quanto à necessidade de compreender os benefícios que a aprendizagem de segunda língua traria a eles. Ainda que essas questões sejam incipientes na área de estudos de aquisição de segunda língua, o reconhecimento da sua importância é fundamental. A questão concernente à capacidade de aprendizes idosos aprenderem uma segunda língua remete novamente à problemática da idade da aquisição. Kliesch et al. (2018) afirmam que o mito de que quanto mais cedo se der a aquisição, melhor, foi rejeitado e que há agora um consenso de que há poucas vantagens relacionadas a uma aquisição precoce quanto à velocidade de aprendizado e ao sucesso do aprendizado. Ao contrário, estudos já mostraram que o "clima" e o contexto de sala de aula, a motivação, a exposição extracurricular à L2, o conhecimento anterior da L2, as habilidades de literacia e a intensidade e o tipo de instrução são preditores mais relevantes no sucesso em longo prazo da aquisição de segunda língua (PFENNINGER, 2017).

A questão da capacidade de aprendizes idosos, em Kliesch et al. (2018) considerados os aprendizes com mais de 60 anos, é perpassada por preconceitos sociais. Assim, é comum que aprendizes idosos tenham uma percepção autodepreciativa das suas capacidades e, segundo Ramírez Gómez (2016), mesmo os instrutores de L2 podem assumir uma atitude discriminatória em sala de aula ao subestimar as habilidades dos aprendizes. Em um interessante estudo de Gómez Bedoya (2008 apud KLIESCH et al., 2018) com falantes de japonês aprendizes de espanhol, apenas metade dos 40 participantes com mais de 60 anos sentiu que a idade tinha um efeito 
negativo no sucesso do seu aprendizado de $L 2$, enquanto a outra metade não percebeu efeito nenhum. Os aprendizes com mais de 60 anos também eram mais motivados e dedicados que os aprendizes mais jovens, além de serem contra a ideia de grupos separados por idade.

Ainda quanto à capacidade dos aprendizes idosos, Singleton e Pfenninger (2018) afirmam que a "literatura neurocognitiva sobre envelhecimento, de uma forma geral, sugere que o cérebro preserva grande parte da sua plasticidade mesmo em uma idade avançada e permanece receptivo a novas línguas" (p. 265). Uma das dificuldades nos estudos de aquisição de segunda língua por indivíduos idosos está na descoberta de que diferenças individuais parecem ter um papel mais importante durante 0 envelhecimento do que no caso de aprendizes mais jovens, umas delas a capacidade auditiva (SINGLETON; PFENNINGER, 2018). Assim, a qualidade do estímulo de segunda língua e a quantidade parecem ser cruciais (MACKEY; SACHS, 2012).

Para além das habilidades percebidas em sala de aula, cabe ressaltar que a importância prática do estudo de aquisição de segunda língua por aprendizes idosos está justamente na possibilidade de usar durante 0 processo de ensino-aprendizagem 0 conhecimento acerca das peculiaridades do aprendiz idoso. Sabe-se, por exemplo, que durante o envelhecimento, o cérebro passa por alterações funcionais e estruturais que têm um impacto na cognição. Como já mencionado, o aprendizado de segunda língua envolve inibição de L1, memorização, atenção e metacognição (KLIESCH et al, 2018). Em um estudo de Martensson (2012), ficou demonstrado que aprendizes com mais dificuldades apresentaram aumento na massa cinzenta em áreas frontais, indicando uma ativação do lobo frontal. Levando em consideração que, conforme estudo de Fjell et al. (2012), durante o envelhecimento saudável há redução nas áreas corticais temporais e pré-frontais, pode-se esperar que aprendizes idosos tenham que exercer maior esforço cognitivo a fim de compensar essa perda. Esse resultado é correlato ao estudo de
Wong et al. (2007), em que os aprendizes bemsucedidos revelaram alterações plásticas em áreas corticais associadas à audição, enquanto os aprendizes com dificuldade no processo de aprendizagem fonética de sua língua apresentaram atividade frontal difusa, o que indicaria um maior esforço cognitivo. Esses aprendizes extrapolaram as funções auditivas durante 0 processo de aprendizagem. Considerando que há alta incidência de problemas de audição em indivíduos com mais de 65 anos (KLIESCH et al., 2018) e o fato de que a aquisição de segunda língua parece fazer uso do domínio auditivo, pode-se concluir que, se não tratada a perda de audição, o aprendizado pode se tornar mais cognitivamente trabalhoso.

Por fim, é válido citar alguns resultados trazidos por Singleton e Pfenninger (2018) sobre a aquisição de segunda língua por idosos: a saúde cognitiva, a motivação, o nível de ansiedade e conhecimento prévio de L2 são alguns dos fatores que explicam a grande variação individual dos aprendizes durante o aprendizado de L2; mesmo treinamentos de L2 de curta duração (como um curso de 14 horas durante uma semana) podem trazer benefícios para aprendizes de $\mathrm{L} 2$, tanto jovens quanto adultos, no que concerne a atenção (por exemplo, a capacidade de mudar o foco da atenção) (BAK et al., 2016 apud SINGLETON; PFENNINGER, 2018); idosos com melhor memória de trabalho parecem ter maior sucesso na aprendizagem de L2 (MACKEY; SACKS, 2012); finalmente, o aprendizado de L2 pode prevenir o isolamento e proporcionar autoestima e autonomia.

\section{Considerações finais}

Sabe-se que o envelhecimento cobra um custo cognitivo dos indivíduos. As perdas na memória episódica e nas funções executivas e as falhas na produção verbal, declínios já conhecidos pelos pesquisadores da área de envelhecimento neurocognitivo, podem levar a prejuízos emocionais e psicológicos. Assim, não é incomum que os idosos tenham uma visão autodepreciativa das suas capacidades, uma vez que, além do que de fato 
caracteriza o envelhecimento, a sociedade é permeada de estereótipos que minam a autoestima do idoso. Segundo, Singleton e Pfenninger (2018), "as atitudes em relação a aprendizes idosos - mesmo entre alguns pesquisadores - tendem a ser desinformadas, movidas por clichés e condescendentes" (p. 268).

Já há um número vasto de pesquisas que investigam a relação entre 0 bilinguismo e 0 envelhecimento. Ainda que não se possa dizer que essa relação esteja completamente elucidada - pelo contrário, ainda há controvérsias quanto às pesquisas que consideram o bilinguismo como um fator protetivo contra o aparecimento dos primeiros sintomas de demência -, pouco se sabe como as peculiaridades cognitivas do cérebro idoso pode impactar o seu processo de aprendizagem de segunda língua. De acordo com os dados apresentados ao longo deste estudo, considera-se que o aprendizado de L2, por ser uma atividade cognitivamente desafiadora, pode trazer benefícios ao idoso, tanto no nível cognitivo no aprimoramento da reserva cognitiva, como no nível socioafetivo, ao proporcionar oportunidades de socialização. Dessa forma, percebe-se a necessidade de investigações que se debrucem a compreender esse processo de aquisição com o objetivo de tornar o ensino de segunda língua mais benéfico ao público idoso.

\section{Referências}

ALLADI, Suvarna et al. Bilingualism delays age at onset of dementia, independent of education and immigration status. Neurology, v. 81, n. 22, p. 19381944, 2013.

ANTONIOU, Mark; WRIGHT, Sarah M. Uncovering the mechanisms responsible for why language learning may promote healthy cognitive aging. Frontiers in psychology, v. 8, p. 2217, 2017.

ARDILA, Alfredo; RAMOS, Eliane. Bilingualism and aging. Perspectives on Communication Disorders and Sciences in Culturally and Linguistically Diverse (CLD) Populations, v. 17, n. 3, p. 74-81, 2010.

BAK, Thomas $\mathrm{H}$. The impact of bilingualism on cognitive ageing and dementia. Linguistic Approaches to Bilingualism, v. 6, n. 1, p. 205-226, 2016.
BIALYSTOK, Ellen et al. Bilingualism, aging, and cognitive control: evidence from the Simon task. Psychology and aging, v. 19, n. 2, p. 290, 2004.

; CRAIK, Fergus I. M.; FREEDMAN, Morris. Bilingualism as a protection against the onset of symptoms of dementia. Neuropsychologia, v. 45, n. 2, p. 459-464, 2007.

BILLIG, Johanna Dagort; SCHOLL, Ana Paula. The impact of bilingualism and aging on inhibitory control and working memory. Organon, v. 26, n. 51, 2011.

BURKE, Deborah $M$. et al. On the tip of the tongue: What causes word finding failures in young and older adults? Journal of memory and language, v. 30, n. 5, p. 542-579, 1991.

BURKE, Deborah M.; SHAFTO, Meredith A. Aging and language production. Current directions in psychological science, v. 13, n. 1, p. 21-24, 2004.

COSTA, Albert; HERNÁNDEZ, Mireia; SEBASTIÁNGALLÉS, Núria. Bilingualism aids conflict resolution: Evidence from the ANT task. Cognition, v. 106, n. 1, p. 59-86, 2008.

CRAIK, Fergus I. M.; BIALYSTOK, Ellen; FREEDMAN, Morris. Delaying the onset of Alzheimer disease: bilingualism as a form of cognitive reserve. Neurology, v. 75, n. 19, p. 1726-1729, 2010.

DE PICCIOTTO, Janet; FRIEDLAND, Deborah. Verbal fluency in elderly bilingual speakers: Normative data and preliminary application to Alzheimer's disease. Folia Phoniatrica et Logopaedica, v. 53, n. 3, p. 145-152, 2001.

DIAMOND, Adele. The early development of executive functions. Lifespan cognition: Mechanisms of change, v. 210, p. 70-95, 2006.

DRAG, Lauren L.; BIELIAUSKAS, Linas A. Contemporary review 2009: cognitive aging. Journal of geriatric psychiatry and neurology, v. 23, n. 2, p. 75-93, 2010.

FJELL, Anders M. et al. One-year brain atrophy evident in healthy aging. Journal of Neuroscience, v. 29, n. 48, p. 15223-15231, 2009.

GARCIA, Vítor R. M. Learning English in the elderly: an analysis of motivational factors and language learning strategies. BELT-Brazilian English Language Teaching Journal, v. 8, n. 2, p. 234-256.

GOLLAN, Tamar H. et al. The bilingual effect on Boston Naming Test performance. Journal of the International Neuropsychological Society, v. 13, n. 2, p. 197-208, 2007.

Tamar H. et al. Degree of bilingualism predicts age of diagnosis of Alzheimer's disease in low- 
education but not in highly educated Hispanics. Neuropsychologia, v. 49, n. 14, p. 38263830, 2011.

GÓMEZ, Danya Ramírez. Language teaching and the older adult: The significance of experience. Bristol: Multilingual Matters, 2016. 272 p.

KLIESCH, Maria et al. Research on second language acquisition in old adulthood: What we have and what we need. Second language acquisition; 120, p. 48-76, 2018.

LAWTON, Deborah M.; GASQUOINE, Philip G.; WEIMER, Amy A. Age of dementia diagnosis in community dwelling bilingual and monolingual Hispanic Americans. Cortex, v. 66, p. 141-145, 2015.

MACKAY, Donald G.; JAMES, Lori E. Sequencing, speech production, and selective effects of aging on phonological and morphological speech errors. Psychology and Aging, v. 19, n. 1, p. 93, 2004.

MACKEY, Alison; SACHS, Rebecca. Older learners in SLA research: A first look at working memory, feedback, and L2 development. Language Learning, v. 62, n. 3, p. 704-740, 2012.

MÅRTENSSON, Johan et al. Growth of languagerelated brain areas after foreign language learning. Neurolmage, v. 63, n. 1, p. 240-244, 2012.

ORTEGA, Lourdes. Understanding second language acquisition. Abingdon: Routledge, 2014. 320 p.

PARK, D. C. et al. Models of visuospatial and verbal memory across the lifespan. Psychology and Aging, vol. 17, n. 2, p. 299-320, jun, 2002.

PFENNINGER, Simone E. et al. Not so individual after all: An ecological approach to age as an individual difference variable in a classroom. Studies in Second Language Learning and Teaching, v. 7, n. 1, p. 19-46, 2017.
REUTER-LORENZ, Patricia A.; PARK, Denise C. How does it STAC up? Revisiting the scaffolding theory of aging and cognition. Neuropsychology review, v. 24, n. 3, p. 355-370, 2014.

ROSSELLI, Monica et al. Verbal fluency and repetition skills in healthy older Spanish-English bilinguals. Applied neuropsychology, v. 7, n. 1, p. 17-24, 2000.

SANDERS, Amy E. et al. Non-native language use and risk of incident dementia in the elderly. Journal of Alzheimer's Disease, v. 29, n. 1, p. 99-108, 2012.

SCARMEAS, Nikolaos et al. Influence of leisure activity on the incidence of Alzheimer's disease. Neurology, v. 57, n. 12, p. 2236-2242, 2001.

SHAFTO, Meredith A. et al. Word retrieval failures in old age: the relationship between structure and function. Journal of Cognitive Neuroscience, v. 22, n. 7, p. 1530-1540, 2010.

SINGLETON, David; PFENNINGER, Simone E. L2 acquisition in childhood, adulthood and old age. Journal of Second Language Studies, v. 1, n. 2, p. 254-275, 2018.

STERN, Yaakov et al. Influence of education and occupation on the incidence of Alzheimer's disease. Jama, v. 271, n. 13, p. 1004-1010, 1994.

STERN, Yaakov. Cognitive reserve. Neuropsychologia, v. 47, n. 10, p. 20152028, 2009.

WONG, Patrick CM; PERRACHIONE, Tyler K.; PARRISH, Todd B. Neural characteristics of successful and less successful speech and word learning in adults. Human brain mapping, v. 28, n. 10, p. 995-1006, 2007.

\section{COMO CITAR ESSE ARTIGO}

SCHLEDER DE BORBA, Lívia. O impacto cognitivo do bilinguismo no envelhecimento e a aquisição de segunda língua por aprendizes idosos. Signo, Santa Cruz do Sul, v. 45, n. 82, jan. 2020. ISSN 1982-2014. Disponível em: <https://online.unisc.br/seer/index.php/signo/article/view/14317>.

Acesso em: doi:https://doi.org/10.17058/signo.v45i82.14317. 